\title{
PRESENCIA DE LA MUJER EN LAA MEDICINA GUAYAQUILEÑA
}

\author{
DRA. MARIANA BARCIA DE ALTAMIRANO \\ Hospital Alejandro Mann, Guayaqui?
}

La presencia cada vez mayor de las mujeres en la Universidad es sólo un aspecto general del trabajo femenino y del papel de la mujer en la Sociedad.

El esfuerzo de ella por combatir las limitaciones evidentes que aún hoy se encuentra y muy poco justificable, hay que entenderlo como un esfuerzo hacia la liberación de la mujer por el trabajo.

El trabajo femenino a través de la Historia no es una novedad, pero si es cierto que en todas las sociedades empezando desde las más primitivas ha existido una distinción muy estricta, entre ocupaciones propias de los hombres y propias de las mujeres. Pero también es cierto que en las sociedades, desde las primitivas, las ooupaciones femeninas no sólo se han reducido a la maternidad y a las labores domésticas, sino que incluyen actividades productivas y económicas, por ejemplo: los hombres guardan el ganado $\mathrm{y}$ las mujeres tejen, o los hombres cazan y las mujeres recogen las plantas y frutos, o sea que en todos los tiempos las mujeres han trabajado y a veces duramente.

Con el desarrollo de las fuerzas de la producción y la división en clases sociales, la clase dominante no requiere que la mujer trabaje y colabore en el proceso productivo y hasta pasa a ser símbolo de distinción el no trabajar, aún en carreras profesionales que demandan una gran preparación académica y científica.

La Universidad del siglo XIX, es sólo para hombres, las hijas de la burguesía se preparan exclusivamente para sus labores.

Esto determina la menor frecuencia de la presencia de la mujer en la Universidad y una desigual distribución en las distintas facultades, esta desigual distribución resulta de un conjunto de opiniones colectivas que se resumen en lo siguiente:

1. Las mujeres tienen menos aptitudes o menos aficiones que los hom- 
bres para ciertas profesiones y por lo tanto es natural que se las preparen en menor escala.

2. El trabajo profesional tiene menos sentido para las mujeres que para los hombres y por tanto, es natural que no estudie profesiones a las que no se dedique exclusivamente.

3. Los posibles usuarios confían menos en las mujeres que en los hombres para ciertos ejercicios profesionales, por lo tanto las mujeres no se preparan en profesiones en las que no van a tener aceptación.

Esto anterior se basa en prejuicios que se van venciendo con el tiempo.

Cuál es el origen de las diferencias entre hombres y mujeres en la orientación profesional?

Es el resultado de unas diferencias psicobiológicas hereditarias o es consecuencia de estereotipos sociales?

Las diferencias físicas contribuyen a diferencias sexuales en las conductas.

Platón, en su "República" dice que no hay diferencias entre la naturaleza masculina y femenina y que por tanto, no se pueden diferenciar las capacidades o funciones femeninas de las masculinas.

Las últimas generaciones intuyen y tratan de conseguir una sociedad diferente, en la que la mujer pueda tomar un lugar compatible, no sólo con la imagen de su papel, sino con una concepción nueva de la educación, del matrimonio, de la familia, y de la organización del trabajo.

Día a día son más la mujeres que se enfrentan a nuevos modos de vida, co- mo consecuencia se proyectan a los de. más de un modo diferente.

El número reducido de profesiones $\mathrm{y}$ actividades femeninas se ha visto au. mentado como consecuencia de la ley de la oferta y la demanda. Sin embar. go, se ha observado que cuando una profesión pasa a ser femenina se des. valoriza y pasa a ser menos renumerada, como ejemplo tenemos lo que sucede en el campo de la medicina en EE UU. y Rusia.

En EE. UU. sólo un 5,07\% de las profesionales médicas son mujeres, en la URSS la misma profesión ha pasado a ser femenina, el $76 \%$ son mujeres. No se diría que las mujeres americanas 0 europeas están peor dotadias para esta profesión que las rusas. Tampoco puede decirse que la medicina rusa esté atrasada, ni que las soviéticas desempeñen mal la profesión, pues en pocos lustros Rusia ha conseguido colocarse entre los países en donde la mortalidad infantil es menor y en donde la media de vida es más alta.

En el mundo del trabajo, la mujer más instruida está peor pagada que el hombre, el prejuicio del sexo es muy fuerte. En nuestro medio, hoy día todos estos prejuicios se van superando en su mayoría, la mujer va a la universidad tanto a filosofía como a ciencias y su preparación hace que ocupe cargos tan importantes como el hombre. Interviene en el desarrollo del país y su preparación intelectual, su responsabilidad, su dedicación le han hecho merecedora de un rol muy alto en la sociedad. 
Hay mujeres médicas en Guayaquil que han ocupado y ocupan la presidencia de Sociedades Científicas como la Sociedad de Pediatría, Saciedad de Reumatología, Cardiología, Oftalmología, y muchas médicas dentro de la Universidad han ocupado importantes cargos en la docencia y siguen aportando en el desarrollo educativo. Sin embargo, concluimos como dice el correo de la Unesco: "La discriminación contra la mujer sean políticas, legales, sociales o económicas no llegarán a superarse sin la cooperación activa de hombres y mujeres que deben aunar fuerzas para persuadir a los gobiernos y a la sociedad que le garantice el acceso de la mujer a la plena igualdad y la ponga en condiciones de participar plenamente en el desarrollo y progreso del país".

Para apreciar la intervención de las médicas de Guayaquii en el desarrollo de la Medicina, presentamos los datos siguientes:

Analizando el número de médicos graduados en la Facultad de Ciencias Médicas de Guayaquil encontramos lo siguiente:

Desde 1868 a 1985 se han graduado 6.322: hombres 4.717 que corresponden al $74,61 \%$ y mujeres 1.605 que correspanden al $25,39 \%$.

La primera mujer graduada fue María Luisa Muller, el 13 de agosto de 1924, en la década del 30 no hubo graduadas y aparecen nuevamente en número reducido las mujeres graduadas en las décadas del 40-50-60, incrementándose este múmero en la década del 70, y constituir en la década del 80 el
$50 \%$ de graduadas en relación con el número de médicos.

No todos los médicos graduados se afilian al Colegio de Médicos del Guayas y por lo tanto el número de médicos registrados en este colegio es menor.

Número de médicos inscritos: 4.686, tabulados por razones técnicas: 3.210 , que corresponden a hombres 2.584 que representa el $80,5 \%$ y a mujeres 626 que corresponden al $19,5 \%$.

De este número de médicas se tiene:

Trabajando en ejercicio privado: 405 que corresponde al $64,7 \%$

Trabajandio en las siguientes instituciones:

Otras entidades empleadoras de carácter privado son: ASTRA, DINARIN, AUTORIDAD PORTUARIA, HOTEL CONTINENTAL, BANCO CENTRAL, HOSPITAL MILITAR, todas ellas con 1 mujer médica que representa el $0,16 \%$.

Médicas que laboran en la facultad de Ciencias Médicas como docentes: Profesoras a tiempo completo 2, Profesoras a tiempo parcial 1.18, Profesoras a tiempo parcial 2, 22; Jefes de Clínica 35 , Ayudantes profesionales 26.

De acuerdo a las especialidades, la mujer médica en la provincia del Guayas incursiona en un número mayor 0 menor en casi todas las especialidades. Entre ellas mencionamos las siguientes: 
En el Hospital del Niño:

En el Hospital Alejandro Mann:

21 que corresponde al $3,35 \%$

En el Hospital Vernaza:

En el Hospital Guayaquil:

En el Hospital Lorenzo Ponce:

En la Maternidad Sotomayor:

En el I.E.S.S:

En el Instituto de Hiegiene

En Solca:

En la Dirección Provincial de Salud

del Guayas

En la Subsearetaría de Salud

\begin{tabular}{|c|c|c|}
\hline & & " \\
\hline & & $"$ \\
\hline & & ", \\
\hline & & $"$ \\
\hline & , & $"$ \\
\hline & , & $"$ \\
\hline & ", & $"$ \\
\hline & ", & $"$ \\
\hline & " & $"$ \\
\hline & ", & $"$ \\
\hline
\end{tabular}

$\begin{array}{lrr}\text { Especialidades } & \text { Total } & \text { Mujeres } \\ \text { Anestesiología } & 53 & 10 \\ \text { Cardiología } & 38 & 3 \\ \text { Cirugía plástica } & 17 & 1 \\ \text { Dermatología } & 29 & 8 \\ \text { Endocrinología } & 9 & 1 \\ \text { Gastroenterología } & 14 & 1 \\ \text { Genetista } & & 1 \\ \text { Gineco-obstetricia } & 151 & 24 \\ \text { Hematología } & 6 & 3 \\ \text { Laboratorio clínico } & 2 & 1 \\ \text { Medicina físico y } & \text { reha- } & \\ \text { bilitación } & 13 & 4 \\ \text { Medicina interna } & 110 & 14 \\ \text { Oftalmología } & 30 & 8 \\ \text { Neurología } & 10 & 1 \\ \text { Psiquiatría } & 51 & 7 \\ \text { Salud pública } & 17 & 3 \\ \text { Neumología } & 29 & 3 \\ \text { Radiología } & 16 & 1 \\ \text { Reumatología } & 7 & 3 \\ \text { Pediatría } & 172 & 54 \\ \text { Traumatología } & 33 & 1 \\ \text { Urología } & 22 & 1\end{array}$

